\title{
STUDI PERSEBARAN TUMBUHAN AKWAY (Drimys sp.) DI PAPUA
}

\section{(Plant Distribution Study of Akway [Drimys sp.] in Papua)}

\author{
Vina O.R. Solekha ${ }^{1}$ dan Soetjipto Moeljono ${ }^{1 凶}$ \\ Jurusan Kehutanan, Fakultas Kehutanan Universitas Papua Manokwari, Papua Barat, \\ 98314. Tlp/Fax: +62986211065. \\ $\triangle$ Penulis Korespondensi: Email: s.moeljono@unipa.ac.id \\ Diterima: 12 Jan 2018| Disetujui: 02 Feb 2018
}

\begin{abstract}
Abstrak
Tujuan dari penelitian ini ialah untuk mengkaji sebaran jenis-jenis tumbuhan akway (Drimys sp.) di dataran Papua dengan mengali informasi bedasarkan referensi sains dan koleksi pustaka akademik dari berbagai sumber. Data yang dikumpulkan selanjutnya diuraikan berdasarkan ciri dan karakteristik morofloginya serta sebaran dan informasi lokasi ditemukannya. Hasil studi dan kajian ini menunjukkan bahwa terdapat 18 jenis tumbuhan akway yang tersebar dan terekam jejak akademisnya. Sebagian besar jenis-jenis akway tumbuh pada ketinggian di atas $1.000 \mathrm{~m}$ dpl dengan karakteristik tumbuhan yang relatif kecil perawakannya. Dari total jumlah jenis tumbuan ini, terdapat hanya 3 jenis yang secara kontinyu dimanfaatkan oleh masyarakat dalam kehidupan keseharian mereka. Namun dengan tinggi tingkat perambahan hutan dan sumberdaya alam, dikhawatirkan jenis-jenis tumbuhan akway dapat punah kalau tidak ada upaya pelestarian dan konservasinya.
\end{abstract}

Kata kunci: Persebaran tumbuhan, jenis akway, karakteristik morfologi, biodiversitas, papuasia.

\begin{abstract}
This study aimed to reveal information regarding the natural distribution of akway (Drimys sp.) in the island of Papua by way of compelling related information based on scientific references and academic paper from multiple sources. Data that gathered then elaborated according to its morphological characteristic as well as the distribution and place where the plants found. The result noticed there were 18 types of akway species found and recorded along the Papuan island. Most of these plants have been growth above 1,000 $\mathrm{m}$ above sea level with a relatively small characteristic of living plant. In addition, from those, there were three species that have been regularly used in the daily life among traditional communities. However, in line with a high rate of forest conversion and extraction of natural resources, it was alarmed that the future of the plant was in danger status or even can cause extinction if there were no conservation and preservation efforts taken.
\end{abstract}

Keywords: plant distribution, akway species, morphological attribute, biodiversity, papuasia. 


\section{PENDAHULUAN}

Indonesia merupakan salah satu negara dari lima negara mega biodiversitas di dunia serta yang memiliki keanekaragaman hayati tinggi (Rintelen et al. 2017). Indonesia memiliki keunikan tersendiri disamping memiliki keanekaragaman hayati tinggi, yaitu Indonesia mempunyai areal tipe ekosistem yang lengkap dan letak geografisnya merupakan peralihan antara Benua Asia dan Benua Australia. Selain itu di Indonesia terdapat banyak hewan dan tumbuhan langka, serta hewan dan tumbuhan endemik (Force 2010).

Indonesia dengan luas wilayah $1,3 \%$ dari seluruh luas muka bumi memiliki $10 \%$ tumbuhan berbunga, $12 \%$ mamalia, $17 \%$ jenis burung, dan $25 \%$ jenis ikan. Indonesia terletak di daerah tropis dengan curah hujan tinggi sehingga menyebabkan keanekaragaman hayati yang tinggi dibandingkan dengan daerah subtropis (iklim sedang) dan kutub (iklim kutub) (Ministry of Environment and Forestry of Indonesia 2014). Tingginya keanekaragaman hayati di Indonesia ini terlihat dari berbagai macam ekosistem yang ada di Indonesia, seperti: ekosistem pantai, ekosistem hutan bakau, ekosistem padang rumput, ekosistem hutan hujan tropis, ekosistem air tawar, ekosistem air laut, ekosistem savanna, dan lain-lain. Masing-masing ekosistem ini memiliki keaneragaman hayati tersendiri (Force 2010).

Tumbuhan di Indonesia merupakan bagian dari geografi tumbuhan Malesiana. Kawasan flora Malesiana meliputi Malaysia, Singapura, Brunei Darussalam dan New Guinea (Papuasia). Flora yang tumbuh di Malaysia, Indonesia, dan Filipina sering disebut sebagai kelompok flora Malesiana. Kawasan Timur
Malesiana (East Malesiana) mulai dari sebagian Sulawesi, Maluku dan Papuasia (Papua dan Papua New Guinea) memiliki flora yang berbeda dengan kawasan barat Malesiana (West Malesiana). Kawasan Barat Malesiana didominasi oleh tumbuhan dari suku Dipterocarpaceae (tumbuhan dengan biji bersayap), sedangkan kawsan timur Malesiana didominasi oleh tumbuhan jambujambuan (Eugenia sp.), matoa (Pometia pinnata), beringin (Ficus sp.), dan Araucaria sp. (Steenis 1950).

Papua memiliki keanekaragaman hayati yang sangat tinggi karena ditunjang oleh hutan hujan tropis yang luas. Sebagian besar $(70 \%)$ hutan hujan tropis Papua yang belum terganggu dan merupakan salah satu dari tiga wilderness (rimba) di dunia selain hutan Amazon (Amerika Latin) dan Kongo (Afrika). Selanjutnya sekitar $50 \%$ dari keseluruhan keanekaragaman hayati Indonesia terdapat di Papua. Selain itu pulau Papua merupakan tempat hidup dari berbagai jenis flora fauna yang unik dan endemik, (70\% dari total keanekaragaman hayati Papua adalah spesies endemik), artinya biota tersebut hanya ditemukan di Papua, salah satunya yaitu kayu Akway (Drimys spp.) (Bertho 2011).

Drimys spp. adalah salah satu marga dari suku Winteraceae. Jenis ini tersebar dari selatan Meksiko ke ujung selatan Amerika Selatan dan Papuasia, termasuk dalam tumbuhan dikotil (bijinya berkeping dua), memiliki daun dan kulit aromatik, serta beberapa yang digunakan untuk mengekstrak minyak esensial (Johns 1997). Sehingga dengan demikian, tujuan dari penelitian ini tidak lain untuk mengetahui penyebaran jenis-jenis tumbuhan akway yang terdapat di hutan Papua. 


\section{METODE PENELITIAN}

Penelitian ini dilaksanakan pada April hingga Mei tahun 2011 yang bertempat di Manokwari degan menggunakan metode deskriptif komparatif literatur dan pustaka sain berkaitan dengan jenis tumbuhan akway. Referensi yang diperoleh antara lain bersumber dari skripsi, tesis dan database pustaka dari perpustakaan secara online serta rujukan berita online dan blog yang dapat dipercaya sumber dan akurasi beritanya. Hasil penemuan pustaka dan referensi tersebut selanjutnya dicatat dan dilakukan identifikasi mendalam melalui komparasi jenis dan status tumbuhan tersebut. Data kemudian ditampilkan dalam bentuk tabel dan deskripsi serta foto sebagai rujukan jenis tumbuhan yang dimaksud.

\section{HASIL DAN PEMBAHASAN}

Berdasarkan hasil penelitian yang dilakukan, ditemukan delapan belas spesies Drimys yang terdapat di seluruh hutan Papua, yakni: Drimys arfakensis Gibbs, Drimys beccariana Gibbs, Drimys piperita Hooker F, Drimys elongata Ridley, Drimys montis-wihelmi Hoogland, Drimys oligandra A. C. Smith, Drimys winterii Forst, Drimys pittosporoides Diels, Drimys dictyophlebia Diels, Drimys rubiginosa A. C. Sm, Drimys pachyphylla Diels, Drimys lamii Diels, Drimys obovata A. C. Sm, Drimys versteegii Diels, Drimys fistulosa Diels, Drimys cyclopum Diels, Drimys tenuiflora Kan \& Hat, dan Drimys microphylla A. C. Sm (Harvard herbaria 2010; Paisey 2008).

\section{Persebaran Akway di Papua}

Penyebaran Akway di Indonesia hanya terdapat di wilayah Papua. Daerah penyebaran akway di Papua secara geografis berdasarkan database koleksi spesimen yang diperoleh dapat disajikan pada Tabel 1.

\section{Morfologi dan Karakteristik Jenis Yang Ditemukan}

1. Drimys arfakensis Gibbs.

Deskripsi: Drimys arfakensis Gibbs., memiliki tipe status yakni tipe fragmen. Distribusi: Provinsi Papua, Gunung Arfak, pada ketinggian 7000 - 8000 kaki. Ekologi: Hutan primer dan sekunder. Koleksi spesimen: dikoleksi oleh L. S Gibbs dengan nomor koleksi 5533 pada tahun 1917.

2. Drimys beccariana Gibbs.

Deskripsi: tinggi rata-rata tumbuhan ini hanya 2,39 meter dengan jumlah cabang 3 per pohon dan memiliki ratarata diameter $1,77 \mathrm{~cm}$ serta pepagan bagian luarnya halus. Tumbuhan ini memiliki model arsitektur rouh, arah tumbuh cabang terhadap batang utama adalah $<45^{\circ}$. Kayu akway merah kecil memiliki ukuran panjang daun $4,38 \mathrm{~cm}$ dengan warna daun hijau (green yellow), susunan daun adalah bertumpu, bentuk helaian daun lanset serta bagian tepi daun rata. Memiliki bunga berwarna merah muda yang terdapat pada bagian terminal dengan biji yang berbulir. Bunga dari tumbuhan ini adalah hemaprodit. Klasifikasi akway merah kecil, Kingdom: Spermatophyta, Divisi: Magnoliophyta, Kelas: Magnoliopsida, Subklas: Asteridae, Ordo: Canenalles, Famili: Winteraceae, Genus: Drimys, Species: $D$. beccariana. Drimys beccariana pertama kali diidentifikasikan oleh Gibbs sehingga disebut dengan Drimys beccariana. Gibbs. Distribusi: Provinsi Papua, Menyambouw. Ekologi: Hutan primer 
dan sekunder. Koleksi spesimen : E.K Paisey, tahun 2008.

Tabel 1. Penyebaran jenis tumbuhan akway di Papua berdasarkan identifikasi spesimen.

\begin{tabular}{|c|c|c|}
\hline No. & Nama Jenis & Lokasi \\
\hline 1. & Drimys arfakensis Gibbs. & Provinsi Papua Barat, G. Arfak. \\
\hline 2. & Drimys beccariana Gibbs. & Provinsi Papua Barat, Manokwari distrik Menyambouw. \\
\hline 3. & Drimys elongata Ridley. & Provinsi Papua, G. Cartenz. \\
\hline 4. & $\begin{array}{l}\text { Drimys montis-wihelmi } \\
\text { Hoogland. }\end{array}$ & $\begin{array}{l}\text { Provinsi Eastern Highland, dekat Danau Aunde, east slope } \\
\text { of Mount Wilhelm, Papua New Guinea. }\end{array}$ \\
\hline 5. & Drimys oligandra A.C. Smith. & Provinsi Papua, sungai Idenburg. \\
\hline 6. & Drimys piperita Hooker F. & $\begin{array}{l}\text { Provinsi Papua, danau Habbema, sungai Idenburg, Sungai } \\
\text { Bele, Anggi (g. Arfak),Menyambouw, Danau Giji, Papua } \\
\text { New Guinea (Provinsi Central, Murray Pass, Whalton } \\
\text { Range). }\end{array}$ \\
\hline 7. & Drimys winterii Forst. & Provinsi Papua Barat, Manokwari distrik Menyambouw. \\
\hline 8. & Drimys pittosporoides Diels. & Provinsi Papua, Kabupaten Jaywijaya. \\
\hline 9. & Drimys dictyophlebia Diels. & Papua New Guinea, gunung Hellwig. \\
\hline 10. & Drimys rubiginosa A.C. Sm. & Provinsi Papua, sungai Idenburg (Taritatu). \\
\hline 11. & Drimys pachyphylla Diels. & Provinsi Papua, sungai Memberamo. \\
\hline 12. & Drimys lamii Diels. & Provinsi Papua, kabupaten Jayawijaya, Memberamo. \\
\hline 13. & Drimys obovata A.C. Sm. & $\begin{array}{l}\text { Provinsi Papua, kabupaten Jayawijaya, sekitar Danau } \\
\text { Habema. }\end{array}$ \\
\hline 14. & Drimys versteegii Diels. & $\begin{array}{l}\text { Papua New Guinea, Wichmanngenergle, Hubrecht } \\
\text { complex. }\end{array}$ \\
\hline 15. & Drimys fistulosa Diels. & $\begin{array}{l}\text { Provinsi Papua, Kabupaten Jayawijaya, sungai } \\
\text { Memberamo. }\end{array}$ \\
\hline 16. & Drimys cyclopum Diels. & Provinsi Papua, Kabupaten Jayapura, gunung Cycloop. \\
\hline 17. & Drimys tenuiflora Kan \& Hat. & $\begin{array}{l}\text { Provinsi Papua Barat, kabupaten Manokwari, distrik Anggi, } \\
\text { gunung Arfak, hutan Mossy. }\end{array}$ \\
\hline 18. & Drimys microphylla A.C. Sm. & $\begin{array}{l}\text { Provinsi Papua Barat, kabupaten Manokwari, distrik Anggi, } \\
\text { gunung Arfak, hutan Mossy. }\end{array}$ \\
\hline
\end{tabular}

\section{Data sekunder spesimen}

3. Drimys elongata Ridley.

Deskripsi : Drimys elongata Ridley memiliki tipe status isotype. Distribusi : Provinsi Papua, Gunung Carstenz. Ekologi: tumbuh pada hutan primer dan hutan sekunder dengan ketinggian 750$1650 \mathrm{~m}$ dpl.. Koleksi spesimen: dikoleksi oleh C. Boden-Kloss pada tahun 1916.

4. Drimys montis-wihelmi Hoogland.

Deskripsi: Drimys montis-wihelmi Hoogland., memiliki tipe status isotype. Berkembang biak dengan bunga.
Distribusi: Papua New Guinea, Eastern Highlands, sekitar Danau Aunde, sebelah timur Gunung Wilhelm. Ekologi: hutan primer dan hutan sekunder. Koleksi spesimen: dikoleksi oleh R. D. Hoogland \& R. Pullen dengan nomor koleksi 5674 pada tanggal 19 Juli 1956.

5. Drimys oligandra A. C. Smith.

Deskripsi: Drimys oligandra A. C. Smith., memiliki tipe status isotype. Distribusi: Provinsi Papua, sungai Idenburg (Taritatu), $6 \mathrm{~km}$ barat daya dari 
Bernhard Camp pada ketinggian $1300 \mathrm{~m}$ dpl. Habitatnya pada hutan hujan dataran tinggi. Ekologi: Hutan primer dan hutan sekunder. Koleksi spesimen: Brass. L. J pada tanggal 1 Februari 1939.

6. Drimys piperita Hooker F.

Deskripsi: Drimys piperita Hooker F., memiliki tipe status isotype. Reproduksi melalui bunga. Karakter morfologi yang merupakan ciri dari kayu akway ini adalah memiliki tinggi rata-rata 3,09 meter dengan model arsitekturnya adalah sccarone, rata-rata jumlah cabang perpohonnya adalah sebanyak 4 cabang. Tumbuhan ini memiliki rata-rata ukuran panjang daun $3,43 \mathrm{~cm}$ dan rata-rata diameter batangnya adalah $2 \mathrm{~cm}$. Pepagan bagian luar batang atau kulit luar adalah halus dengan arah pertumbuhan cabang terhadap batang adalah $45^{\circ}-90^{\circ}$. Tumbuhan ini memiliki bentuk helaian oblong dengan warna daun hijau tua dan susunan daun adalah deccusate dan berlekuk pada bagian ujung daun serta memiliki pucuk yang berwarna orange (yellow red). Klasifikasi akway merah besar, Kingdom: Spermatophyta, Divisi: Magnoliophyta, Kelas: Magnoliopsida, Subklas: Asteridae, Ordo: Canenalles: Winteraceae, Genus: Drimys, Species: $D$. piperita. Distribusi: Provinsi Papua, sekitar kawasan Danau Habema, 3.225 m dpl; Barat daya dari Bernhard Camp 15 $\mathrm{km}$, sungai Idenburg dengan ketinggian $1.800 \mathrm{~m} \mathrm{dpl} ; 18 \mathrm{~km}$ barat daya dari Bernhard Camp, sungai Idenburg, 2.150 $\mathrm{m} \mathrm{dpl} ; 6 \mathrm{~km}$ barat daya dari Bernhard Camp, sungai Idenburg, 1300 m; Sungai Bele $18 \mathrm{~km}$ sebelah tenggara Danau Habema, 2.350 m dpl; Angi, Pegunungan Arfak: Hutan Iray, danau Giji, $1.900 \mathrm{~m}$ dpl; Angi, pegunungan Arfak. Perjalanan ke Anggi dari Momi, $1.800 \mathrm{~m}$ dpl. Papua New Guinea, Central, Murray Pass,
Wharton Range. Ekologi: hutan primer dan hutan sekunder. Koleksi spesimen: dikoleksi oleh Romer Von pada tanggal 1 November 1909. Koleksi oleh L. J. Brass nomor koleksi 4519 pada September 1933, kemudian nomor koleksi 9068 pada bulan Agustus 1938, koleksi nomor 12006 pada bulan Januari 1939, Koleksi nomor 11295 pada bulan November 1938, Koleksi nomor 12629 pada buan Februari 1939, Koleksi nomor 12975, pada bulan Februari 1939. Koleksi oleh R. Kanehira \& S. Hatusima, nomor koleksi 13408 pada tanggal 5 April 1940. Kemudian nomor koleksi 13935 pada tanggal 7 April 1940.

7. Drimys winterii Forst.

Deskripsi: kayu akway ini dikenal masyarakat sebagai kayu akway putih. Karakter morfologi yang dimiliki oleh kayu akway putih ini adalah rata-rata tinggi pohon adalah 2,34 $\mathrm{m}$ dengan model arsitektur sccarone. Rata-rata diameter batang adalah $2,15 \mathrm{~cm}$ dengan pepagan bagian luar batang sedang, jumlah cabang perpohon adalah 3-4 cabang. Arah tumbuh cabang terhadap batang utama adalah $45^{\circ}-90^{\circ}$. Kayu akway putih ini memiliki ukuran panjang daun $3,80 \mathrm{~cm}$ dengan susunan daun adalah deccusate dan warna daun adalah hijau (green yellow). Bentuk helaian daun adalah lanset dengan perbandingan panjang dan lebar adalah 3-5: $1 \mathrm{~cm}$ serta bagian tepi daunnya yang rata. Sistem klasifikasi $D$. winterii, Kingdom: Spermatophyta, Divisi: Magnoliophyta, Kelas: Magnoliopsida, Subklas: Asteridae, Ordo: Canenalles, Famili: Winteraceae, Genus: Drimys, Species: D. winterii. Distribusi: Provinsi Papua Barat, Menyambouw. Ekologi: hutaan primer dan hutan sekunder. Koleksi spesimen : E.K Paisey tahun 2008. 
8. Drimys pittosporoides Diels.

Deskripsi: Drimys pittosporoides Diels., memiliki tipe status isotype. Distribusi: Provinsi Papua, Kabupaten Jayawijaya pada ketinggian $3.250 \mathrm{~m}$ dpl dengan koordinat $3^{\circ} 28^{\prime} 12^{\prime}$ LS, 138 27'00” BT. Ekologi: hutan primer dan hutan sekunder. Koleksi spesimen: Lam, H. J pada tanggal 17 Oktober 1920.

9. Drimys dictyophlebia Diels.

Deskripsi: Drimys dictyophlebia Diels., memiliki tipe status type isotype. Reproduksi dengan bunga. Distribusi: Papua New Guinea, Gunung Hellwig pada ketinggian $1.900 \mathrm{~m}$ dpl. Ekologi: hutan primer dan hutan sekunder. Koleksi spesimen: Pulle. A. pada tanggal 27 Desember 1912.

\section{Drimys rubiginosa A. C. Sm.}

Deskripsi: Drimys rubiginosa A. C. Sm., memiliki tipe status type lectoisotype. Reproduksi dengan bunga. Distribusi: Provinsi Papua, Sungai Idenburg (Taritatu), $18 \mathrm{~km}$ barat daya Bernhard Camp pada ketinggian $2.150 \mathrm{~m}$ dpl. Habitatnya pada hutan mossy. Ekologi: hutan primer dan hutan sekunder. Koleksi spesimen: Brass. L.J. pada tanggal 1 Februari 1939.

\section{Drimys pachyphylla Diels.}

Deskripsi: Drimys pachyphylla Diels., memiliki tipe status tipe lectoisotype. Reproduksi dengan bunga. Distribusi: Provinsi Papua, Kabupaten Jayawijaya, Sungai Memberamo pada ketinggian $3.200 \mathrm{~m}$ dpl dengan koordinat $3^{\circ} 28^{\prime} 12^{\prime}$ ' LS, 138 27'0” BT. Ekologi: hutan primer dan hutan sekunder. Koleksi spesimen: Lam H.J. pada tanggal 29 Oktober 1920.

\section{Drimys lamii Diels.}

Deskripsi: Drimys lamii Diels., memiliki tipe status lectoisotype dengan tinggi $2 \mathrm{~m}$ dan reproduksi dengan bunga. Distribusi: Provinsi Papua, Kabupaten Jayawijaya, Sungai Memberamo pada ketinggian $2.900 \mathrm{~m}$ dpl dengan koordinat $3^{\circ} 28^{\prime} 12^{\prime \prime}$ LS, $138^{\circ} 27^{\prime} 0$ ' BT dan pada ketinggian $2.480 \mathrm{~m}$ dpl dengan koordinat 3०28'12" LS, 138²7'0” BT. Ekologi: hutan primer dan hutan sekunder. Koleksi spesimen: Lam H.J. pada tanggal 31 Oktober 1920 dan pada tanggal 10 November 1920.

13. Drimys obovata A. C. Sm.

Deskripsi: Drimys obovata A. C. Sm., memiliki tipe status isotype dan reproduksi dengan bunga. Distribusi: Provinsi Papua, Kabupaten Jayawijaya, $18 \mathrm{~km}$ tenggara Danau Habema pada ketinggian $2.350 \mathrm{~m}$ dpl, dengan koordinat 47'48” LS, 13840'12” BT. Ekologi: hutan primer dan hutan sekunder. Koleksi spesimen: Brass. L.J. pada tanggal 1 November 1938.

14. Drimys versteegii Diels.

Deskripsi: Drimys versteegii Diels., memiliki tipe status type lectoisotype dan memiliki bunga. Distribusi: Papua New Guinea, Wichmanngenergle, Hubrecht Complex pada ketinggian $3.100 \mathrm{~m}$ dpl. Ekologi: hutan primer dan hutan sekunder. Koleksi spesimen: Pulle A. pada tanggal 7 Februari 1913.

\section{Drimys fistulosa Diels.}

Deskripsi: Drimys fistulosa Diels., memiliki tipe status lectoisotype dan reproduksinya dengan bunga. Distribusi: Provinsi Papua, Kabupaten Jayawijaya, Sungai Memberamo pada ketinggian $3.250 \mathrm{~m}$ dpl dengan koordinat $3^{\circ} 28^{\prime} 12^{\prime \prime}$ LS, 138 27'0" BT. Ekologi: hutan primer dan hutan sekunder. Koleksi spesimen: Lam H.J. pada tanggal 17 Oktober 1920.

16. Drimys cyclopum Diels.

Deskripsi: Drimys cyclopum Diels., memiliki tipe status isotype dan memiliki bunga. Distribusi: Provinsi Papua, Kabupaten Jayapura, Gunung Cycloop 
pada ketinggian $1.800 \mathrm{~m}$ dpl dengan koordinat $2^{\circ} 31^{\prime} 48^{\prime \prime}$ LS, $140^{\circ} 36^{\prime} 0^{\prime \prime}$ BT. Habitatnya terdapat di Bosch. Ekologi: hutan primer dan hutan sekunder. Koleksi spesimen: Gjellerup K. pada tanggal 20 Juni 1911.

\section{Drimys tenuiflora Kan \& Hat.}

Deskripsi: Drimys tenuiflora Kan \& Hat., memiliki tipe status isotype dan bereproduksi dengan bunga. Bunga berwarna putih dengan tinggi tumbuhan 1 m. Distribusi: Provinsi Papua Barat, Kabupaten Manokwari, Distrik Anggi, Gunung Arfak di hutan Mossy pada ketinggian $1.800 \mathrm{~m}$ dpl dengan koordinat $1^{\circ} 22^{\prime} 48^{\prime \prime}$ LS, 13358'12” BT. Ekologi: hutan primer dan hutan sekunder. Koleksi spesimen: Kanehira R. pada tanggal 5 April 1940.

\section{Drimys microphylla A. C. Sm.}

Deskripsi : Drimys microphylla A. C. Sm., memiliki tipe status type. Bunga berwarna putih. Distribusi: Provinsi Papua, Sungai Idenburg (Taritatu), 15 km barat daya dari Bernhard Camp pada ketinggian $1.800 \mathrm{~m}$ dpl. Ekologi: hutan primer dan hutan sekunder. Koleksi spesimen: Brass. L.J. pada tanggal 1 Januari 1939.

\section{Jenis-jenis Akway Dimanfaatkan}

Jenis-jenis akway yang dimanfaatkan oleh masyarakat Papua terdiri dari tiga jenis: yaitu kayu akway merah besar (Drimys piperita Hook.), kayu akway merah kecil (Drimys beccariana Gibbs.), dan kayu akway putih (Drimys winterii Forst.) (Paisey 2008).

\section{Perkembangan Konservasi Akway di Papua}

Akway di Papua belum dikelola dengan baik, sehingga pembudidayaan atau pemeliharaannya belum dilakukan.
Hingga saat ini kayu akway hanya dimanfaatkan oleh masyarakat Papua, tetapi belum dilakukan upaya konservasi yang nyata. Dikhawatirkan jika tingkat pemanfaatan yang tinggi secara terus menerus tanpa ada usaha konservasi, maka populasi jenis tumbuhan akway tersebut akan punah. Kayu akway tumbuh secara alami di Papua dan tidak cocok untuk upaya perbanyakan melalu stek. Sehingga diharapkan baik kepada masyarakat yang beriteraksi langsung dengan tanaman akway maupun instansi terkait untuk melakukan pemeliharaan terhadap populasi pertumbuhan akway sehingga ketersediaannya di alam tetap terjaga.

\section{DAFTAR PUSTAKA}

Bertho R. 2011. Keanekaragaman hayati di Papua. http://fmipauncen.com/?p=544. [11 April 2011]

Force D. 2008. Keanekaragaman hayati di Indonesia.

http://grandmall10.wordpress.com/20 10/02/10/keanekaragaman-hayatidiindonesia/.

[11 April 2011]

Harvard University Herbaria Database. 2010.

http://kiki.huh.harvard.edu/databases/ specimen search.php?mode $=$ details \&id=135962. [12 april 2011].

Johns R J. 1997. The forest trees of Irian Jaya. Royal Botanic Gardens Kew, Richmond, Surrey, England.

Ministry of Environment and Forestry of Indonesia. 2014. The fifth national report of Indonesia to the Convention on Biological Diversity. Deputy Minister of Environmental Degradation Control and Climate Change, Ministry of Environmental 
and Forestry. Jalan D.I. Panjaitan Kav.24, Jakarta Timur.

Paisey EK. 2008. Kajian morfologi dan kimia kayu akway (Drimys sp.) sebagai afrodisiak endemik Papua. Tesis Magister Sains pada Program Studi Agronomi Fakultas Pertanian IPB. Bogor. (Tidak diterbitkan). http://repository.ipb.ac.id/handle/1234 56789/9076. [21 April 2011]. von Ritelen K, Arida E and Hauser C. 2017. A review of biodiversity-related issues and challenges in megadiverse Indonesia and other Southeast Asian countries. Research Ideas and Outcomes, doi: 10.3897/rio.3.e20860. van Steenis CGCJ. 1950. Flora malesiana I. Vol. I. Series I. Spermatophyta. Noordhoff-Koeff. Jakarta. 